University of Wollongong

Research Online

Faculty of Social Sciences - Papers (Archive) Faculty of Arts, Social Sciences \& Humanities

2018

Parenting and neighbouring in the consolidating city: The emotional geographies of sound in apartments

\author{
Sophie-May Kerr \\ University of Wollongong, smk534@uowmail.edu.au \\ Christopher R. Gibson \\ University of Wollongong, cgibson@uow.edu.au \\ Natascha Klocker \\ University of Wollongong, natascha@uow.edu.au
}

Follow this and additional works at: https://ro.uow.edu.au/sspapers

Part of the Education Commons, and the Social and Behavioral Sciences Commons

Research Online is the open access institutional repository for the University of Wollongong. For further information contact the UOW Library: research-pubs@uow.edu.au 


\title{
Parenting and neighbouring in the consolidating city: The emotional geographies of sound in apartments
}

\author{
Abstract \\ Apartment residents share space vertically and horizontally, and apartment materiality shapes their \\ experiences of sound and space. Across diverse contexts, rapid urban population growth has prompted a \\ shift towards higher-density dwellings - often a pronounced departure from cultural norms of detached, \\ suburban housing. Yet little is known about the everyday emotional experiences of apartment residents. \\ This paper draws on insights gathered from families, with children, living in apartments in Sydney, \\ Australia - a city undergoing profound densification. Developers typically market high-rise apartments as \\ a transitional housing form for singles and couples. However, a sizeable number of families with children \\ now live in apartments, and as our findings suggest, they struggle with expectations that children (and \\ their sounds) do not belong. These families' experiences of high-density living reveal how the materiality \\ of sound and built form interact with cultural norms to shape how apartment spaces are understood and \\ inhabited. So too, how the emotions of everyday life co-construct apartment spaces and social relations \\ (both within families and between neighbours). Physical proximity leads to tensions around acoustics and \\ privacy, while apartment materiality creates an emotional dilemma between being a good parent and a \\ good neighbour. Sound can lead to feelings of guilt, shame, and stress. We discuss such travails, as well \\ as families' spatial, temporal and material coping strategies. Cultural and technical norms, we contend, \\ must shift to support families with children in the consolidating vertical city.

\section{Disciplines} \\ Education | Social and Behavioral Sciences

\section{Publication Details} \\ Kerr, S., Gibson, C. \& Klocker, N. (2018). Parenting and neighbouring in the consolidating city: The \\ emotional geographies of sound in apartments. Emotion, Space and Society, 26 1-8.
}




\title{
Parenting and neighbouring in the consolidating city: The emotional geographies of sound in apartments
}

\author{
Sophie-May Kerr* \\ smk534@uowmail.edu.au \\ Chris Gibson \\ Natascha Klocker
}

Australian Centre for Cultural Environmental Research, School of Geography and Sustainable Communities, University of Wollongong, Australia

*Corresponding author.

"This research has been conducted with the support of the Australian Government Research Training Program Scholarship and the University of Wollongong Global Challenges Program Scholarship.

\begin{abstract}
Apartment residents share space vertically and horizontally, and apartment materiality shapes their experiences of sound and space. Across diverse contexts, rapid urban population growth has prompted a shift towards higher-density dwellings - often a pronounced departure from cultural norms of detached, suburban housing. Yet little is known about the everyday emotional experiences of apartment residents. This paper draws on insights gathered from families, with children, living in apartments in Sydney, Australia - a city undergoing profound densification. Developers typically market high-rise apartments as a transitional housing form for singles and couples. However, a sizeable number of families with children now live in apartments, and as our findings suggest, they struggle with expectations that children (and their sounds) do not belong. These families' experiences of high-density living reveal how the materiality of sound and built form interact with cultural norms to shape how apartment spaces are understood and inhabited. So too, how the emotions of everyday life co-construct apartment spaces and social relations (both within families and between neighbours). Physical proximity leads to tensions around acoustics and privacy, while apartment materiality creates an emotional dilemma between being a good parent and a good neighbour. Sound can lead to feelings of guilt, shame, and stress. We discuss such travails, as well as families' spatial, temporal and material coping strategies. Cultural and technical norms, we contend, must shift to support families with children in the consolidating vertical city.
\end{abstract}

Keywords: Soundscapes; Families; Apartments; Parenting; Neighbouring; Emotions; Verticality

\section{Introduction}

Apartment developments are transforming urban morphology globally. Across diverse contexts where low-density suburbs were previously the norm, this shift towards high-density dwellings represents a major transition from the ideal of detached, suburban housing. This is particularly so for families with children, for whom houses are seen to support middle-class familial values, practices and identities (Dowling and Power, 2012). In contrast to the privacy and space afforded by idealised and often expansive houses (Dowling and Power, 2012), apartments are typically characterised by smaller spaces, close physical proximity and sharing of built features and facilities with unrelated others (Easthope and Judd, 2010). Housing design, materials, size and form iteratively shape everyday practices and experiences (Shove, 2003; Klocker et al., 2012), yet there is little understanding of how apartment-dwellers negotiate their everyday emotional lives. Scholars have called for further qualitative research into experiences of living in apartments, to determine whether urban consolidation and densification policies meet the needs of a diverse population (Gleeson and Sipe, 2006; Easthope and Judd, 2010; Woolcock et al., 2010; Easthope and Tice, 2011).

Our focus is on the everyday lives of families with children; a social group for whom many apartment developments were not explicitly intended. This paper explores the emotional terrain of parenting in apartments, within close proximity to neighbours. While in some contexts, children living in apartments are already common place (for example, Singapore, Hong Kong, Paris and Moscow), apartments have typically been viewed as a transitional stage in the housing cycle of city residents in the USA, Canada and Australia. High-rise apartments in newly densifying cities are envisaged as places for 
young childless couples, young singles or empty nesters. Families are expected to move to detached houses after having children (Fincher, 2004; Easthope et al., 2009). Social and cultural norms position children in apartments as atypical, inappropriate even (Horin, 2011; Harrison, 2012). Planners and developers reproduce such expectations (Fincher, 2004), as evidenced in building design and marketing (Martel et al., 2013; Gower, 2015). Yet apartment living is a growing reality for many families with children. In Sydney, Australia - the location of the current study - families with children under the age of 15 comprised 25 per cent of the city's apartment population in 2016 (ABS, 2016). For some of these families apartment living is a choice based on location and lifestyle (Schwarz, 2017). For others, growing housing unaffordability makes apartment life a financial necessity (Kennedy and Blumer, 2017). It is a circumstance increasingly shared in such cities as Vancouver, Auckland and San Francisco undergoing both real estate booms and rapid densification. Irrespective of motive, families with children are living in apartments, and their numbers are increasing rapidly in neighbourhoods where high-density living has not historically been the norm.

The following section situates this study in a broader body of literature on families, children and the city (Gleeson and Sipe, 2006). We then review relevant research on materiality, sound and home; as well as sound, parenting and surveillance. Our empirical case, based on interviews and home tours with families residing in apartments in Sydney, is presented as a series of vignettes that demonstrate how families struggle with their children's noise, and associated guilt and shame, at different times of night and day. For several of the families interviewed, relationships with neighbours were deeply unsettling, and parents felt undue pressure to compromise on their parenting ideals. In the context of transitions towards higher-density urban morphologies, we argue that sound is a key locus of contestation shaping families' emotional geographies. Accordingly, technical and cultural norms need to shift to be more inclusive of families; and more mindful of how materials, emotions and sound play out in everyday lives.

\section{Families, children and the city}

Around the world, increasing numbers of families reside in higher-density environments (Karsten, 2015). This trend has been attributed to new spatial manifestations of global real estate capital investment (such as grand urban renewal schemes focused on high-rise residential apartments); social changes (e.g. more women in the paid workforce), and the lifestyles enabled by higher-density living due to the proximity of amenities (Karsten, 2007, 2015; Brydon, 2014; Rogers, 2016). While there are a number of benefits to higher-density living, consolidation plans in Sydney (and other cities globally) have been criticised for neglecting families' changing relationships with urban space. The complexity of apartment populations is not reflected in apartment designs, thus creating challenges for diverse household configurations (Easthope and Judd, 2010; Klocker and Gibson, 2013).

Despite such trends, the experiences of families living in apartments with children remain underresearched. The extant literature is predominantly quantitative (Randolph, 2006; Easthope et al., 2009; Easthope and Tice, 2011; Whitzman and Mizrachi, 2012); has tended to focus on lower socio-economic groups (e.g. Randolph, 2006); and on the spaces surrounding apartment complexes, rather than indoor spaces (Whitzman and Mizrachi, 2012). Previous studies have drawn attention to issues facing children and their parents in apartments, relating to the physical environment (e.g. lack of private space) and social context (e.g. safety, affordability). Important insights of relevance to our own research are found in Brydon (2014) and Nethercote and Horne (2016). These qualitative studies have foregrounded the lived experiences of families with children in apartments, including issues relating to internal space (e.g. number of bedrooms, size of living areas and storage challenges). Nethercote and Horne (2016) drew particular attention to the ways in which families mediate intra-familial needs for privacy and separation through time-zoning, interpersonal and socio-material negotiation and readjustments. They also shed light on families' use of shared apartment facilities and sense of community. However, less is known about how interactions between apartment residents - that is, with neighbours - are shaped by the materiality of apartment designs, layouts and features. And moreover, how families respond emotionally to living in apartments, especially ones where children were not originally imagined as inhabitants - and which may be poorly designed to accommodate for their (sometimes noisy) presence.

This paper accordingly explores the emotional experiences of living and parenting in close proximity to unrelated others, sharing physical, social and acoustic space. It considers how the internal materiality of apartments shapes interactions with neighbours, and how parents feel when parenting in this context (with implications for their parenting practices). We adopt a socio-material perspective to explore 
relationships between building materiality, sound, emotions and everyday practices of parenting and neighbouring, within apartments. In so doing, we draw attention to the ways in which emotions are mutually co-constructive of space and social relations.

\section{Materiality, sound and home}

Sound provides an under-utilised sensory departure point for understanding the fabric of urban spaces (Connell and Gibson, 2003; Atkinson, 2007). Nevertheless, inspired by antecedent work in cultural geography on soundscapes (Smith, 1994), an interest in emotional and affective geographies of sound has emerged in recent years, with researchers seeking to better understand the impact of sound on emotions, bodies, place and everyday experiences (Thompson and Biddle, 2013; Duffy et al., 2016; Doughty et al., 2016; Gallagher, 2016; Gallagher et al., 2017). Sound is not merely observed; it is felt, with the capacity to move bodies and affect particular emotions and social relations (Doughty et al., 2016; Gallagher, 2016). Sound has political agency and therefore can be a source of contest or conflict in certain spatio-temporal settings (Revill, 2016).

Duffy and Waitt (2013) argued that attention to the everyday visceral experiences of sound offers new insights into geographies of home. Emotional responses to sound provide an opportunity to understand where the body feels at home and whose (or what) sounds belong (Duffy et al., 2011). Such observations coincide with the relatively recent 'material turn' in housing studies, which foregrounds socio-material interactions between spaces, objects and subjects within the home (Jacobs and Gabriel, 2013; Nansen et al., 2011; Jacobs and Smith, 2008; Blunt, 2005). The home is understood as a material and affective space, 'shaped by everyday practices, lived experiences, social relations, memories and emotions' (Blunt, 2005:506). Research into the materiality of the building and the lived experience of sharing space has provided insights into politics of domesticity, intimacy and privacy (Blunt, 2005; Gorman-Murray, 2007); and into the negotiations that underpin families' daily lives as they share physical and acoustic space (Dowling and Power, 2012).

Despite cities being layered with different sounds, discourses surrounding home are entwined with ideas of personal autonomy and quietude (Adams et al., 2006; Atkinson, 2007). Sounds deemed to intrude into these personal spaces are understood as noise. Insights from literature on noise and acoustics, demonstrate the complexity of distinguishing between sound and noise, as interpretations are highly subjective and dependent on the context of the sound to the listener (Adams et al., 2006; Gallagher et al., 2017). The relative presence or absence of sound prompts visceral reactions that interact with residents' everyday lives in meaningful ways (Atkinson, 2007; Duffy and Waitt, 2013). The implications of being surveilled by sound-prints, leads people to manage themselves in ways which reduce sounds made at different times and places, to avoid becoming a source of annoyance (Atkinson, 2007). And indeed, regulations in apartment blocks frequently demand such self-management. In the state of New South Wales (NSW), where Sydney is located, strata schemes divide buildings into individual 'lots' or units; apartment-owners own their individual lot, and also share ownership of common property with other lot owners (NSW Government, 2015a). Each strata scheme has by-laws that owners, tenants and visitors must follow. The model by-law for residential strata schemes in NSW relating to noise reads: "An owner or occupier of a lot ... must not create any noise on a lot or the common property likely to interfere with the peaceful enjoyment of the owner or occupier of another lot or of any person lawfully using common property" (NSW Government, 2016). Strata by-laws cannot legally restrict children; therefore the regulation of children's sounds occupies an ambiguous space governed by cultural norms. Dominant cultural norms about what is deemed 'appropriate' activity vary temporally: 'day is for activity, labour, and noise. Night is for silence and sleep' (Gallan, 2014:136). The same sound can invoke diverse emotional reactions, reflecting social norms around what kinds of people, sounds and activities 'belong' at different times of day and night (Gallan and Gibson, 2011; Gallan, 2014). As shown later in this paper, these norms weighed heavily on our study participants.

Scholars have begun to explore the relationship between verticality, home and sound/privacy (Mee, 2007; Baker, 2013; Power, 2015). Baker (2013) explored the interactions of residents living in highdensity housing in Newcastle, Australia. Tensions around noise and discordant home-making values were evident between proximate residents within apartment blocks, attributed to differences in residents' tenure and age (Baker, 2013). For Baker (2013) participants, moderating noise levels and thus being a 'considerate neighbour'was critical. While this experience is not unique to higher-density forms, the significance of such neighbouring practices is increased due to the intensities of contact experienced by 
apartment residents (Baker, 2013). Neighbours in such contexts have to negotiate their privacy both when in public spaces and in the private or personal domain. While residents might be in a 'visually' private space (i.e. behind closed doors), they can still be exposed to the noises and smells made by others (Mee, 2007).

Power (2015) has explored how 'nuisance noise' is self-governed by residents in Sydney apartments. The ideal resident or 'good' neighbour ought not disturb other residents with personal and household sounds -in her case, from pets (Power, 2015). Building materiality influences the way sound travels, impacting residents' ability to identify its origin. Easthope and Judd (2010) found that higherdensity residents rated noise highly as a disruptive behaviour, particularly when apartments contained hard floor surfaces. When living in close proximity, the feeling of being free from surveillance while 'at home' is constrained, particularly when noise-related issues are brought to residents' attention. While existing noise research has examined the health effects of annoyance induced by neighbour noise (Maschke and Niemann, 2007), the emotional stress of those deemed responsible for creating 'nuisance noise' warrants further exploration. This paper responds accordingly, examining emotional geographies of parenting in the soundscape of high-density living.

\section{Sound, parenting and surveillance}

Following Aitken (2000: 582) work on fathering, we understand parenting as 'a daily emotional practice that is negotiated, contested and resisted differently in different spaces'. Sound is key to such negotiations, as it regularly invokes moral judgement from others, leading to parental discomfort and adjustments to parenting practices. The surveillance of children's sound in diverse spaces is the subject of growing research. Boyer and Spinney (2016) discussed the difficult emotions mothers experience while navigating public transport with infants. Their study participants experienced anxiety when travelling with a crying baby in a confined space. Mothers felt judged or out of place because they knew their crying babies were disturbing other passengers (Boyer and Spinney, 2016). Similarly, Small and Harris (2014) explored aeromobility and parenting, shedding light on the angst and intolerance of plane passengers towards parents with crying babies. In such settings, judgements of 'good' or 'bad' parenting (or indeed bad passengering) have emotional implications.

Strata buildings can also be sites where parents face hyper-surveillance of their parenting practices and sounds. A key example came to light through a media story that revealed a Sydney family was threatened with a \$550 fine for having 'noisy' children (Chung, 2016). Despite by-laws not explicitly restricting children, the letter threatening a noise fine claimed that the family was 'breaching strata bylaws' due to 'excessive noise' coming from the apartment 'from early in the morning to very late at night on a regular basis' (Chung, 2016). The family was warned that their children's sounds were disturbing other residents, leaving the parents feeling uncomfortable and discriminated against in this setting. Probyn (2004) has described shame as the feeling of being out-of-place, with seemingly no place to hide. While shame is one of the most intimate of feelings, it is brought into being through proximity to others (Probyn, 2004). As we detail below, shame was felt regularly by our study participants.

Recent relevant work in children's geographies, meanwhile, assists in deciphering how children, youth and teenagers are constructed as in or out of place (Matthews and Limb, 1999; Skelton, 2000; Jones, 2008). Such work highlights how children are seen as out of place in certain public spaces. In this paper, children and families can also be seen as out of place in certain kinds of domestic/private spaces, complicating the usual narrative that children belong at home. Apartments are imagined as adult spaces and children are 'outsiders', restricted and ordered by adult authority.

In what follows, we detail empirically how moral and emotional geographies of parenting unfurl in a consolidating urban landscape. We understand emotions (and moral judgements) as being spatially constituted (Castree et al., 2013) - in this case, through the particular material and acoustic properties of apartment buildings. Our empirical narratives are organised around night and day, the everyday temporalities around which proximity, sound, and cultural norms intersect (Gallan and Gibson, 2011; Gallan, 2014). The participants' stories demonstrate the capacity of children's sounds to elicit feelings of guilt and shame; prompting behavioural and material strategies that endeavour to appease neighbours.

\section{Research methods}


We explored the experiences of 17 families living in apartments, with children, in the Greater Sydney Metropolitan region (including Wollongong) (see Table 1). Most lived in middle to outer ring suburbs - zones of the city where apartment developments have not dominated historically, but where many new approvals and constructions have been located.

Table 1 Participant attribute table (pseudonyms have been used when requested)

\begin{tabular}{|c|c|c|c|}
\hline \multicolumn{4}{|l|}{ alt-text: Table 1} \\
\hline $\begin{array}{c}\text { Name of parent/s who participated } \\
\text { in interview }\end{array}$ & $\begin{array}{l}\text { Number of people in } \\
\text { household }\end{array}$ & $\begin{array}{l}\text { Number of } \\
\text { bedrooms }\end{array}$ & Tenure \\
\hline Paul & 2 adults, 2 children & 2 & Owners \\
\hline Natalie & 2 adults, 1 child & 2 & Renters \\
\hline Darren and Vivian & 2 adults, 1 child & 2 & Renters \\
\hline Rhiannon & 2 adults, 3 children & 4 & Owners \\
\hline Samantha & 2 adults, 2 children & 2 & Renters \\
\hline Melanie & 2 adults, 2 children & 3 & Owners \\
\hline Ruth & 2 adults, 2 children & 2 & Renters \\
\hline Anna & 2 adults, 1 child & 2 & Renters \\
\hline Richard and Francesca & 2 adults, 3 children & 2 & Renters \\
\hline Rebecca & 2 adults, 2 children & 2 & Renters \\
\hline Rachel and Tom & 2 adults, 2 children & 2 & Owners \\
\hline Mariam & 3 adults, 2 children & 2 & Renters \\
\hline Amanda & 2 adults, 2 children & 2 & Renters \\
\hline Belinda & 2 adults, 2 children & 3 & Owners \\
\hline Ximena & 2 adults, 1 child & 1 & Renters \\
\hline Linda & 2 adults, 1 child & 2 & Renters \\
\hline Alice and James & 2 adults, 2 children & 2 & Renters \\
\hline
\end{tabular}

Participants were initially recruited through community groups, personal networks and an online article posted on LookUpStrata.com and shared on the 'Apartment Mum' blog. Further participants were recruited via snowballing and word of mouth, particularly through mothers' groups. Participants were chosen based on criterion sampling, according to the following attributes: they must live within the Greater 
Sydney Metropolitan region, must live in a flat, unit or apartment (i.e. adjoined horizontally and vertically) and must have one or more child/ren aged 15 or under living at home. Interviews took place with parents (usually one, but occasionally both). Participants were mostly middle-class and all were heterosexual nuclear families.

A mixed-methods approach was employed, incorporating two semi-structured interviews, floorplan sketches, home tours and photographs. The initial in-depth interviews explored parents' housing histories, the factors taken into account when choosing their apartment, the process of finding a suitable property and involvement in or understanding of strata. Interviews then explored the emotional experiences of sharing space (both as a family and with neighbours). Discussions focused on how certain home spaces were used (for multiple purposes, at different times and by different family members); and experiences of living within close proximity to neighbours, and how this impacted parenting decisions and family life. Floorplan sketches were also incorporated at this stage of the interviews. Participants' sketches of their apartments were used as a prompt for further discussions about certain spaces within the home. Follow-up interviews aimed to gain greater insights into the materiality of the home and the ways in which families negotiate the purchase of household items and associated storage challenges, as well the sharing of 'stuff' with neighbours. Home tours were conducted during follow-up interviews. They provided an opportunity to explore the materiality of the apartment building and triggered new topics of discussion, offering deeper insights into the realities of living with children in an apartment (Tolia-Kelly, 2004). Home tours enabled participants to talk in a material context rather than an abstract one, leading to impromptu stories and often reminding participants of experiences they had not yet shared. Home tours also allowed participants to show changes or adjustments they had made (or would like to make) to their apartments, to make the space work better for their families. Photographs were taken with participants' permission. Data collection finished with a discussion on the overall experience of home in an apartment and future housing aspirations.

Audio-recordings were transcribed verbatim and coded thematically. While each family had a unique story that brought them to their current living arrangement, most had chosen to make sacrifices in terms of dwelling size in order to be able to live in a particular location - for example prioritising proximity to work, a good school, amenities, extended family, public transport and a city or beachside lifestyle. While this paper focuses on sound and the challenges of living in close proximity to others, it is important to note that participants also talked about the positive aspects of higher-density living and many had made deliberate choices to continue living in apartments even though they could afford a house in a different suburb. The data incorporated in this paper focus specifically on sound and related emotions, and the dilemmas of trying to be a good parent and a good neighbour.

\section{The moral and emotional geographies of parenting in apartments}

Discussions about sound were a dominant and emotive component of participants' narratives. The sounds made by their children were always at the forefront of parents' minds and prompted them to make a number of adjustments to their domestic practices and space. Most had made a number of changes to the physical space (e.g. choice of building material, the addition of carpet), and altered their everyday behaviours including their parenting strategies and activities. They made such changes due to their consciousness of neighbours' surveillance and (at times overt) moral judgements. The following two sections focus on key aspects of raising children in apartments that caused challenges for our study participants: sleeping and crying at night, and playing and running during the day. As shown through two detailed research vignettes - organised around the temporalities of night and day - parents' narratives of apartment life centred on sound, noise and shame. The voices of other participants are incorporated to provide additional evidence, as relevant.

\subsection{Anna: "pick up your baby" - the challenges of managing crying during the night}

Anna and her husband live with their one-year-old son in a two bedroom rented apartment in a beachside Sydney suburb. Like many of the participants in this study, they moved into the apartment before having children and have made adjustments to make apartment life work with the expansion of their 
family. Anna revealed that she had been conscious and stressed about sound and proximity since her son was born, aware of how loud her family could be and that the property is poorly soundproofed. This awareness of sound (and associated anxiety and guilt) was exacerbated during the night.

Regardless of housing type, the changing sleep patterns of newborns and children can be testing on the whole family (Gallan, 2014). Parents in this study discussed how the challenges of sleeping problems are more pronounced in apartments. They struggled to find a balance between "not going in too soon and not letting them cry too long because you have got other people to consider" (Anna). Almost all participants explained that the fear of disturbing neighbours impacted on their parenting practices especially their reactiveness to crying (as opposed to trying to teach babies to self-settle or utilising controlled comforting/crying or 'crying it out' methods). After months of getting up several times a night to comfort Jack, and Anna having to breastfeed him back to sleep, Anna and her husband made the decision that it was time to try something different to help their son learn to self-settle and get back to sleep at night:

[W] 're not that kind of 'cry it out' parents but we just thought we haven't tried this before, let's just let him go for a couple of minutes just to see if he'll self-settle to go back to sleep because we'd been up and down, up and down so many times. And so it would have been like maybe two minutes of doing that and you could hear the neighbour downstairs stomping around. It was the middle of the night, 3a.m. or something. I could hear him stomping. I could tell he was having a bit of a tantrum because Jack [son] was having a shocker. And then you know I was just leaving him [Jack] ... and so we went, "Oh okay maybe he's gone to sleep." And then he started again and then we thought okay just two more minutes, we'll just leave him for two more minutes. And so after like two minutes he [the neighbour] called out... "Pick up your baby!" And so when I settled Jack I came back to bed and Luke told me, "Oh the neighbour just called out." And I'm like, "Why did you tell me?" And I was so upset because we are trying our best and we were exhausted ourselves and we just thought maybe in the short-term this is going to be a bit awful but in the long-term if he can learn how to self-settle ... we've never left him to cry before ... It's really hard and so now that really upset me when I heard that he called out for us to pick up our baby ... If I bumped into him the next day I probably would have burst into tears.

Despite being shaken by this experience, Anna and her husband still felt they needed to change things - particularly as she prepared to return to work. Being a new mother, Anna read widely, chatted to other mums and professionals and put a great deal of thought into writing up a plan which consisted of her stopping breastfeeding during the night and her husband going in to settle their son. On their first night trying this new strategy, stress levels were high among the whole family and Jack was 'hysterical'. After 20 min of her husband trying to settle their 'screaming' baby, they swapped and Anna spent a further 45 min trying - before their neighbour reacted again:

One of the neighbours downstairs like banged on the ceiling really loudly ... I felt it on my feet, like it was shaking. And he didn't call out or anything but it was like quite severe. That just kind of added to my stress ... when I got back into bed after the shrieking finished, and he [Jack] went back to sleep, and the stomping on the roof finished ... I just said, "I don't know if I can do that again" ... knowing that, you know they're hearing it all of course, and we felt terrible.

While Anna was reassured the next day by friends that her sleeping plan was the right thing to do to help Jack get to sleep, she felt torn between doing what she believed to be right for her and her family, and being a good neighbour:

If we didn't have those neighbours maybe we would have tried that earlier but I have been really conscious about trying not to let him cry... You don't want to hear our screaming baby. We know that. But we are trying our hardest as well ... I had been doing what I was doing for probably months, because of them ... running in as soon as he cried, because I was conscious that he would wake them up. But I can't do that anymore.

Others parents also reflected on how their efforts to be good neighbours had influenced their parenting decisions:

I've been very like responsive, too responsive to the point where it's probably made his sleeping worse because I've kind of catered to that in order to not annoy the neighbours. (Melanie)

The challenges of negotiating sleep training in an apartment were discussed by almost all participants. For some, the anxiety around sound eased after having neighbours reassure them that they 
couldn't hear, or didn't mind. For others, either personal experiences of tensions with neighbours or stories from friends led to them feeling constantly on-edge or anxious that they were disturbing others every time their child cried at night. Ximena for instance commented: "At night it's sometimes worse and the $5 \mathrm{~min}$ cry seems like an hour for you because you can't shut it down!"

In each of these instances, participants' narratives demonstrated the complex juggling act of parenting within close proximity to others. Deciding on how to best deal with children crying during the night was not just a personal dilemma. Rather, it involved awareness of impacts on others within a shared material space (Boyer and Spinney, 2016), linked to perceptions of what kinds of sounds and noise are, or are not, acceptable at night (Gallan, 2014; Gallagher, 2016), and ultimately, what kinds of people do or do not belong in apartments. The implication being, in a city like Sydney, children do not belong in apartments but instead in detached houses. In line with Baker (2013) findings, parents acknowledged the importance of being considerate neighbours. However, the sounds of crying children were not always easy to control, leaving parents feeling guilty and uncomfortable as aspects of their private lives were exposed to others. While the sounds of children have been discussed in the literature as causing conflicts in apartments (Easthope and Judd, 2010), the emotional experiences of parents who are deemed responsible for controlling this noise add an additional perspective. Parents felt guilty, yet believed that they were doing everything they could to reduce their impact on neighbours - including compromising their own parenting ideals. Feelings of being subject to unjust circumstances permeated our interviews. Parents were acutely aware that cultural norms place pressure on them to reduce their children's noise, rather than expecting other apartment residents to adjust to children's co-presence.

In addition to adjusting parenting strategies, Anna and her husband had also attempted to make alterations to their apartment to reduce noise such as covering internal vents with cardboard to reduce noise travelling through the building. These strategies were not unique. Families talked about closing windows to contain sound and one family even chose to take their baby to their parents' 'big house' in the suburbs for a few days to attempt sleep training away from their apartment, in order to avoid conflict all together.

Wanting to maintain positive relationships with neighbours, Anna, alongside other participants, described feeling the need to be apologetic:

When Jack was first born maybe after a week or two, I baked all of my neighbours muffins and left them on the doorstep to say sorry about the noise and welcome; this is Jack... your new neighbour. And then he had a shocker again maybe at about six months. He was just not sleeping very well so I left on the downstairs neighbour's doorstep like a bottle of wine and some chocolate and some ear plugs, kind of as a joke but kind of not, to say, "Look, really sorry about the noise."

The gifting of chocolate, baked treats or wine was not uncommon from participants who felt they wanted or needed to apologise to neighbours - either after bringing their new baby home for the first time, after an incident (such as a rough night's sleep, sickness or tantrum), or when a new neighbour moved in pre-empting challenges and hoping to establish open communication.

However, parenting anxieties were not limited to night time. Many families also talked about the challenges of reducing noise from their children's activities during the day. Again, they reflected on the balancing act of being a good parent and being a good neighbour: allowing children to play, whilst also being anxious about annoying the neighbours.

\subsection{Alice and James: "imagine trying to teach a crawler that they are not allowed to crawl through the house" - negotiating daytime sounds of play}

Alice and James live with their two children (aged 1 and 3) in a two bedroom apartment in a beachside suburb east of the Sydney CBD. Their rented apartment was their home for almost 10 years before children were even considered. Proximity to amenities and the lifestyle afforded by their location continued to suit them after their children were born. At the time of the interview however, their lives felt constrained by living in close proximity to others, because sound had led to a number of recent tensions with a neighbour (a single man in his 30s) who had moved in next door in the past 18 months. After an initial period of communication about the noise (including Alice and James bringing a gift of brownies 
when he first moved in and trying to do what they could to reduce sound after receiving letters of complaint) - the disputes started.

Alice and James had a number of strategies for managing sound. As we talked about the use of space in the apartment, they described the way they 'corral' their children into one room at a time, by keeping the doors closed continuously, in order to prevent the children running through the house on the floorboards. On an occasion when two doors were left open and their one-year old son did run through their neighbour next door banged on the wall and started imitating stomping on his floor:

He said to me, "I have spoken to other people; this is not a problem anywhere else. You can't let your kids run around in the house ... you should lock them in their bedroom until they learn". So he just did not have any kind of concept of how much you have an influence over your small children ... When he first started complaining Harry [son] was crawling. Imagine trying to teach a crawler that they are not allowed to crawl through the house... You know, he wanted the impossible, and got angry with us when we couldn't deliver that for him. With no kind of seeming effort to understand where we were coming from ... So it is a very difficult position to be in because I always didn't want to upset anyone but there is not much I can do about it ... You can't do anything quietly so you just feel like you are on show all the time. (Alice).

Alice and James reflected on the guilt they felt - both towards their children and their neighbour. Noise from hard floor surfaces is frequently mentioned in existing research as causing disruption for apartment residents (Easthope and Judd, 2010). In addition to closing doors and putting carpet on the floor, Alice and James (among other participants) mentioned they used the television more often than they would prefer, in an attempt to keep their children still and quiet during 'non-sociable hours', such as early in the morning. They also opted not to have friends visit:

I spend most of my time seeing other people with children and, yeah, you have to go to either their house or you know a park or something. Because if they are ... if Phoebe [daughter] is in here she knows not to run, but if there is a friend in here, they are inevitably going to chase each other within seconds and then, yeah, I get really stressed and I spend my time trying to control them. And then it is not fun for anyone. So, yeah, the children not being able to have their friends come and visit really, is not particularly nice. (James)

Several participants had similar experiences, noting the difficulties of controlling children's play behaviour, feeling like the 'fun police' (Paul):

I always feel like I am constantly telling them 'not in here, not in there, don't do that'... I'm constantly worried that we are annoying the neighbours. Because they are kids, they are loud. They don't have a volume button. (Rhiannon)

In Natalie's experience,

Kids, they run, they jump, they shout, they play you know ... and you have to be just worried a little bit and looking at the time and there is people around us you know you can't just do everything ... but he has energy you know, he just have to run. But I will just say to him, 'run slow' (laughs).

Participants found it difficult to 'police' their children's play activities, exasperated but resigned that this is just what comes with living with children in apartments in Sydney, and that this is something which needs to be understood from both sides.

Parents actively 'managed' noise from their children differently depending on the time of day, with evenings and early mornings causing the most anxiety (Gallan, 2014). They had also adopted strategies for minimising sound from certain activities such as singing or dancing. Paul and his wife restricted these activities to certain rooms that didn't adjoin with neighbours. Belinda and her husband had put down foam mats for dancing practice and several families installed carpet, closed windows and timed activities such as instrument practice. Some participants, particularly owner-occupiers, also talked about taking building materials and layout into account when looking for an apartment, with double brick apartments deemed most desirable largely for their capacity to reduce the travel of sound.

Although parents expressed feeling worried and apologetic about their noise, they also felt that they were doing everything they could to try and be considerate. Mothers' groups provided important support networks for parents to reassure each other and share experiences with others - but beyond this, families needed further support. While it was difficult to explain to younger children why they needed to 
be quiet, once children were old enough parents tried to teach their children to be respectful of others who shared the same building. Despite parents undertaking a number of spatial, temporal and material strategies to reduce noise, in some instances sound-related disputes were ongoing. For Alice and James, months of growing tension with their neighbour erupted in the stairwell one day:

It was a rainy Sunday so I was very aware of the noise ... I was actually going out in order to give this guy some peace and quiet... And I think he was going out because he was really annoyed with the noise. So it was like that kind of perfect storm of - you know we were going out to be considerate and he was going out because he was so pissed off with us. He was yelling at me on the - in the hallway - I was like 'Look I am really sorry', and he was like 'Don't you fucking apologise to me ever again!' Like I had only seen him like three times before. He says: 'That is like me going out to a bar, punching someone in the face and then saying I'm sorry mate, and then punching them again and then saying I'm sorry mate, and then punching them again'... if you take someone's power away to apologise what am I left with? What can I do if I can't even say sorry? (Alice)

As Alice reflected on the tensions her family has experienced, she described feeling vulnerable and unsure what else she could do:

I feel like we have entered this entirely new area of discrimination that I had no idea existed before, but is actually quite prevalent among our peers. It is common among the mothers in my mothers' group ... People just don't like children and they don't like children's noise...And you know parenting is hard - you are constantly just what - what do I do with this? How do I stop it? (Laughs) So to have the 'Oh my god I am pissing loads of people off' in the back of your mind as well as having to deal with what is going on is really uncomfortable. I feel really uncomfortable about it.

Alice and James revealed that in addition to the notes, aggressive stomping and confrontation, their property had also been damaged. Their pram was spat in and left out in the rain, plants were poisoned and their children's towels were dragged through mud. While this example is at the more extreme end of the spectrum, several of the families interviewed (including Anna and her husband) had received letters, complaints or had neighbours call out or bang on their walls. While some participants did not have directly negative experiences themselves, almost all felt anxious about sound and had stories of friends who had experienced problems. The politics of noise in apartments extends well beyond parenting too (Silmalis, 2017). As evidenced in this research, participants also felt self-conscious about neighbours hearing other everyday sounds, for example arguments with their partners or going into labour. In a city shifting physically from low to high-density (but without cultural norms and cultures of neighbourliness adjusting in pace), everyday tensions emerge over when and where sounds are appropriate, or when they become noise. For Alice and James, the situation eventually led them to move from their apartment, shortly after they were interviewed for this study. For all the personal benefits of living in a consolidated city, the stress and anxiety over noise ultimately led to a difficult decision that meant sacrificing the inner city lifestyle they had grown to love.

\section{Conclusion}

In cities newly densifying, families living with children in apartments confront a series of cultural norms in their everyday lives - norms that demarcate the home as a place of quietude; that position 'good neighbours' as tranquil ones; and that consider children as belonging elsewhere, in detached suburban dwellings. Problematically, such norms are confronted in material contexts that make it difficult for parents to regulate sound; and which necessitate complicated and emotionally challenging regimes of sound management. The emotions that emerge through parenting within close proximity to others in the increasingly vertical city complicate simplistic narratives of densification as the preferred model of urban development.

As many cities consolidate, shifting priority from low-density suburbs to higher-density modes of living, a growing number of families with children will live in apartments - whether by choice or through financial constraint. Here we have explored the experiences and emotional travails accompanying parenting in high-density environments. Parents' varied strategies for managing everyday life in these shared spaces highlight the need for further support for families and children, as densification continues. In this paper we have offered a contribution to this agenda, revealing the emotional contours of parenting through a focus on sound and associated tensions and conflicts. Our research furthers discussions around 
verticality, home and sound/privacy (cf. Mee, 2007; Baker, 2013; Power, 2015). The lived experience of apartment acoustics provides a lens through which to explore the tensions and negotiations experienced when living in close proximity to others, and the implications of this for parenting emotions and practices in the everyday rhythms of day and night. Parents' narratives shed light on the emotional stress felt by those deemed responsible for 'nuisance noise' (Power, 2015), highlighting the complex emotional geographies of sound in high density living.

Families living in apartments pursue strategies for making everyday life 'work' in vertical living arrangements. Some are behavioural strategies, notably parenting decisions - which require negotiation and understanding from both families and other residents. Other influences relate to the built form, physical structure and design and the building materials. Some participants sought to alter built fabric where they could exert control: installing carpets or covering up air vents. The parents we spoke to tried to be considerate neighbours in myriad ways, due to their awareness of close proximity. Further elucidating this perspective may lead to a shift in neighbourly tolerance, and perhaps even updated understandings of who lives and belongs in apartments.

However, there is only so much that individual apartment owners can change. The wider problem of apartments with poor acoustic design and performance persists. Our interviews point towards structural barriers that can only be overcome if planners and developers acknowledge that apartment demographics have shifted in fundamental ways, and adjust designs and governance accordingly. Those responsible for apartment design and construction ought to be more fully informed by insights from families with children who live in apartments (and from other residents impacted by their sounds).

The findings of this study inform a future publication aimed squarely at discussing practice implications with planners, architects and acoustics engineers. Although the technical implications of our study for better design and building standards are beyond the scope of this current paper, one implication of this research is to encourage apartment design standards that account for a diverse population, not just singles and couples without children. The NSW Government has already acknowledged the growing presence of children in apartments through the recent introduction of regulations that require all apartments to have lockable windows, to prevent falling injuries and death (NSW Government, 2015b). Spaces in which noise-related technical changes could be implemented include more comprehensive building code regulations as well as government support for retrofit acoustic solutions.

Another implication of our research is that shifts in attitude and cultural acceptance of children and their sounds are needed. This is a matter that goes well beyond structural/building design - to the heart of cultural norms and expectations about where children do (and do not) belong (cf. Skelton, 2000). There is potential for strata bodies to lead the way in this cultural shift, by providing increased support for families living in apartments under the banner of antidiscrimination laws. It is incumbent upon those advocating and governing higher-density modes of living to offer greater protection to families like those in this study, who face intimidating and threatening actions from their neighbours in the consolidating vertical city.

\section{References}

Adams M., Cox T., Moore G., Croxford B., Refaee M. and Sharples S., Sustainable soundscapes: noise policy and the urban experience, Urban Stud. 43 (13), 2006, 2385-2398.

Aitken S., Fathering and faltering: "Sorry, but you don't have the necessary accoutrements, Environ. Plan. A 32, 2000, 581-598.

Atkinson R., Ecology of sound: the sonic order or urban space, Urban Stud. 44 (10), 2007, 1905-1917.

Australian Bureau of Statistics, Table Generated Using Dwelling Characteristics, Dwelling Structure and Family Composition Databases, Findings Based on Use of ABS 2016 Census Data in Table Builder Basic, 2016.

Baker T., Home-making in higher density cities: residential experiences in Newcastle, Australia, Urban Policy Res. 31 (3), 2013, 265-279.

Blunt A., Cultural geography: cultural geographies of home, Prog. Hum. Geogr. 29, 2005, 505-515.

Boyer K. and Spinney J., Motherhood, mobility and materiality: material entanglements, journey-making and the process of 'becoming mother, Environ. Plan. D Soc. Space 0 (0), 2016, 1-19.

Brydon A., Families in the City, Masters Thesis2014, University of Melbourne; Melbourne. 
Castree N., Kitchin R. and Rogers A., A Dictionary of Human Geography, 2013, Oxford University Press.

Chung F., Sydney Mum Threatened with a \$550 Fine for Noisy Toddler in Strata Apartment, 2016, news.com.au, last viewed 6/6/17 http://www.news.com.au/finance/real-estate/buying/sydney-mum-threatened-with-550fine-for-noisy-toddler-in-strata-apartment/news-story/dcf61b05c18bb653ae02740ce09f8446.

Connell J. and Gibson C., Sound Tracks, 2003, Routledge; NY.

Doughty K., Duffy M. and Harada T., Practices of emotional and affective geographies of sound, Emot. Space Soc. 20, 2016, 39-41.

Dowling R. and Power E., Sizing home, doing family in Sydney Australia, Hous. Stud. 27 (5), 2012, 605-619.

Duffy M., Waitt G., Gorman-Murray A. and Gibson C., Bodily rhythms: corporeal capacities to engage with festival spaces, Emot. Space Soc. 4 (1), 2011, 17-24.

Duffy M., Waitt G. and Harada T., Making sense of sound: visceral sonic mapping as a research tool, Emot. Space Soc. 20, 2016, 49-57.

Duffy M. and Waitt G., Home sounds: experiential practices and performativities of hearing and listening, Soc. Cult. Geogr. 14 (4), 2013, 466-481.

Easthope H. and Judd S., Living Well in Greater Density, UNSW City Futures Report, City Futures Research Centre, Faculty of the Built Environment, 2010, University of New South Wales.

Easthope H., Tice A. and Randolph B., The Desirable Apartment Life?, UNSW City Futures Report, City Futures Research Centre, Faculty of the Built Environment, 2009, University of New South Wales.

Easthope H. and Tice A., Children in apartments: implications for the compact city, Urban Policy Res. 29 (4), 2011, 415-434.

Fincher R., Gender and life course in the narratives of Melbourne's high-rise housing developers, Aust. Geogr. Stud. 42 (3), 2004, 325-338.

Gallagher M., Sound as affect: difference, power and spatiality, Emot. Space Soc. 20, 2016, 42-48.

Gallagher M., Kanngieser A. and Prior J., Listening geographies: landscape, affect and geotechnologies, Prog. Hum. Geogr. 41 (5), 2017, 618-637.

Gallan B., Becoming Crepuscular: Rethinking the Human Relationship to Day and Night, Doctor of Philosophy thesis2014, University of Wollongong http://ro.uow.edu.au/theses/4187.

Gallan B. and Gibson C., New dawn or new dusk? Beyond the binary of day and night, Environ. Plan. A 43, 2011, 2509-2515.

Gleeson B. and Sipe N., Creating Child Friendly Cities, 2006, Routledge; NY.

Gorman-Murray A., Contesting domestic ideals: queering the Australian home, Aust. Geogr. 38, 2007, 195-213.

Gower A., The False Coin of Our Apartment Dreams: Contemporary Housing Value in Inner City Melbourne, Minor thesis2015, School of design, University of Melbourne.

Harrison N., Is it Unfair to Raise Kids in an Apartment?, 2012 http://www.mamamia.com.au/parenting/shouldchildren-live-in-apartments/, Mamamia, last viewed 7/1/16.

Horin A., Sound Reasons to Complain, 2011, Essential kids, last viewed 7/1/16 http://www.essentialkids.com.au/development-advice/behaviour-discipline/sound-reasons-to-complain20111023-1mf75.

Jacobs K. and Gabriel M., Homes, objects and things, Hous. Theory Soc. 30 (3), 2013, 213-218.

Jacobs J. and Smith S., Living room: rematerializing home, Environ. Plan. A 40, 2008, 515-519.

Jones O., True geography [ ] quickly forgotten, giving away to an adult-imagined universe'. Approaching the otherness of childhood, Children's Geogr. 6 (2), 2008, 195-212.

Karsten L., Housing as a way of life: towards an understanding of middle-class families preference for an urban residential location, Hous. Stud. 22 (1), 2007, 83-98. 
Karsten L., Middle-class Households with children on vertical family living in Hong Kong, Habitat Int. 47, 2015, 241-247.

Kennedy J. and Blumer C., Housing Affordability Crisis Keeps Families Locked Out of Home Ownership, 2017, ABC News, last viewed 31/5/17 http://www.abc.net.au/news/2017-04-30/housing-affordability-locks-outfamilies/8484258.

Klocker N., Gibson C. and Borger E., Living together, but apart: material geographies of everyday sustainability in extended family households, Environ. Plan. A 44, 2012, 2240-2259.

Klocker N. and Gibson C., Looking inwards: extended family living as an urban consolidation alternative, Plan. Theory Pract. 14 (4), 2013, 555-559.

Martel A., Whitzman C., Fincher R., Lawther P., Woodcock I. and Tucker D., Getting to Yes: overcoming barriers to affordable family friendly housing in inner Melbourne, In: Paper Presented at 6th State of Australian Cities Conference, 2013, Sydney, November 27-29, 2013.

Maschke C. and Niemann H., Health effects of annoyance induced by neighbour noise, Noise Control Eng. J. 55 (3), 2007, 348-356.

Matthews H. and Limb M., Defining an agenda for the geography of children: review and prospect, Prog. Hum. Geogr. 23 (1), 1999, 61-90.

Mee K., I Ain't been to heaven Yet? Living here, this is heaven to me': public housing and the making of home in inner Newcastle, Hous. Theory Soc. 24 (3), 2007, 207-228.

Nansen B., Arnold M., Gibbs M. and Davis H., Dwelling with media stuff: latencies and logics of materiality in four Australian homes, Environ. Plan. D Soc. Space 29, 2011, 693-715.

Nethercote M. and Horne R., Ordinary vertical urbanisms: city apartments and the everyday geographies of highrise families, Environ. Plan. A 48 (8), 2016, 1581-1598.

New South Wales Government, Buying into a Strata Scheme, 2015a, last viewed 6/6/17 http://www.fairtrading.nsw.gov.au/ftw/Tenants_and_home_owners/Buying_property/Buying_into_a_strata _scheme.page?.

New South Wales Government, Window Safety Device Requirements, 2015b, last viewed 13/6/17 http://www.fairtrading.nsw.gov.au/ftw/Tenants_and_home_owners/Strata_schemes/Window_and_balcony _safety/Window_safety_device_requirements.page.

New South Wales Government, Strata Schemes Management Regulation 2016-Schedule 3 Model By-laws for Residential Strata Scheme, 2016, last viewed 6/6/17

http://www.legislation.nsw.gov.au/\#/view/regulation/2016/501/sch3.

Power E., Placing community self-governance: building materialities, nuisance noise and neighbouring in selfgoverning communities, Urban Stud. 52 (2), 2015, 245-260.

Probyn E., Everyday shame, Cult. Stud. 18 (2-3), 2004, 328-349.

Randolph B., Delivering the compact city in Australia: current trends and future implications, Urban Policy Res. 24 (4), 2006, 473-490.

Revill G., How is space made in sound? Spatial mediation, critical phenomenology and the political agency of sound, Prog. Hum. Geogr. 40 (2), 2016, 240-256.

Rogers D., The Geopolitics of Real Estate: Reconfiguring Property, Capital and Rights, 2016, Rowman \& Littlefield; London.

Schwarz K., The families choosing to raise their kids in flats, News.com.au, 2017, last viewed 31/5/17 http://www.news.com.au/finance/real-estate/buying/the-families-choosing-to-raise-their-kids-inflats/news-story/453193ebf543f0ae951b7ce3b6e78be3.

Shove E., Comfort, Cleanliness + Convenience - the Social Organisation of Normality, 2003, Berg; Oxford.

Silmalis L., What You Hate Most about Your Neighbours: the Top Complaints about Living in a Unit Block, 2017, last viewed 6/6/17 http://www.dailytelegraph.com.au/news/nsw/loud-weeing-complaints-on-the- 
rise-with-an-increase-of-strata-dwellers-seeking-mediation/newsstory/25cbc9479bccfc039ea3caafcc955558.

Skelton T., In: Holloway S. and Valentine G., (Eds.), Nothing to Do, Nowhere to Go?” Teenage Girls and 'public' Space in the Rhonda Valleys', in Children's Geographies: Playing, Living, Learning, 2000, Routledge; London, 80-99.

Small J. and Harris C., Crying babies on planes: aeromobility and parenting, Ann. Tour. Res. 48, 2014, $27-41$.

Smith S.J., Soundscape, Area 26 (3), 1994, 232-240.

Thompson M. and Biddle I., Sound, Music, Affect: Theorizing Sonic Experience, 2013, Bloomsbury Academic; NY.

Tolia-Kelly D., Materialising post-colonial geographies: examining the textual landscapes of migration in the South Asian home, Geoforum 35, 2004, 675-888.

Whitzman C. and Mizrachi D., Creating child-friendly high-rise environments: beyond wastelands and glasshouses, Urban Policy Res. 30 (3), 2012, 233-249, Karsten 2009.

Woolcock G., Gleeson B. and Randolph B., Urban research and child-friendly cities: a new Australian outline, Children's Geogr. 8 (2), 2010, 177-192. 